\title{
Urban attributes and regional differences in productivity: evidence from the external economics of Brazilian micro-regions from 2000 - 2010
}

\author{
Rodrigo Ferreira Simões ${ }^{a^{*}}$, Elton Eduardo Freitas ${ }^{b}$ \\ ${ }^{a}$ Centre for Development and Regional Planning (CEDEPLAR) at Federal University of Minas Gerais, Belo Horizonte, MG, Brazil. \\ b CEDEPLAR, Federal University of Minas Gerais, Belo Horizonte, MG, Brazil. E-mail: eltonfreitas@cedeplar.ufmg.br \\ *Corresponding author's E-mail: rodrigo.simoes@cedeplar.ufmg.br
}

\begin{abstract}
H I G H L I G H T S :
1. Identifies the extent to which the local productive structure of a city leverages external economies of scale.

2. Formal employment data is grouped into segments according to its level of technological intensity.

3. Medium-High- and High-Technology industry segments have advantages only in diversified urban centers.

4. Low- and Medium-Low-Technology industries have more advantages in intermediate-sized urban centers
\end{abstract}

\begin{tabular}{|c|c|}
\hline Article History & A B S T R A C T \\
\hline Received: 16-01-2014 & This study aims to identify the extent to which the local productive structure of a city \\
\hline Accepted: 27-02-2014 & leverages external economies of scale. Formal employment data is grouped into \\
\hline Available online: 28-02-2014 & $\begin{array}{l}\text { segments according to its level of technological intensity. The model is estimated using } \\
\text { panel data. The results suggest evidences of local externalities like location/MAR and }\end{array}$ \\
\hline Keywords: & urbanization/Jacobs. The results also indicate that the Medium-High- and High- \\
\hline External economies; & Technology industry segments have advantages only in diversified urban centers, while \\
\hline Productivity; & the Low- and Medium-Low-Technology industries have more advantages in \\
\hline Urban attributes. & intermediate-sized urban centers, specialized in few industrial activities. \\
\hline JEL Classification: & \\
\hline R11; R12. & DOI: http://dx.doi.org/10.18533/jefs.v2i01.51 \\
\hline
\end{tabular}

\subsection{Introduction}

A central tendency in the literature concerns the attempt to understand why economic activities tend to be geographically concentrated and how the bases of the local economies structure and shape the income inequalities between regions and people. These issues have become more relevant in those countries with a large geographical area, high population and different stages of sectoral or spatial development.

The Brazilian economy provides an interesting example of capitalist expansion with deep spatial income inequalities. In the 1970s, when the Brazilian economy accelerated in its industrialization process and achieved extraordinary growth rates as compared to international standards at the time, studies were commonly performed to understand the factors determining regional inequalities in Brazil.

Following a period of stagnation during the 1980s, the Brazilian economy underwent major structural changes in the 1990s. During the latter, Brazil observed the consolidation of price stability, changes in the exchange rate regime and openings in commerce and finance. Brazil's process of external insertion also deepened, as the country's market opened up to foreign products. This brought greater competitiveness to the domestic industry. 
In this productive restructuring environment, urbanization acquired a prominent role, for it received a significant portion of public investment and presented the advantages of agglomeration economies. Thus, strategies for developing and supporting localized productive agglomerations gained importance in regional and local development policies - especially as regards employment and income generation. These strategies aimed attacking advantage of the positive effects produced by productive agglomerations, thus fostering the competitiveness of companies and the region.

The literature on agglomeration economies relates the growth of industrial activity to the increased productivity of firms. The latter arises from external economies of scale or local externalities, according to the productive structure of the region. In fact, this is the argument several authors (Glaeser et al., 1992; Henderson, 1974; Eckestein and Eaton, 1997; Luca, 2001; etc.) use in order to justify that the region is the natural focus, or a natural laboratory, for empirical verification (Henderson et al., 1995). Kaldor (1994) highlight this, pointing out that increasing returns to scale constitute the key factor of economic growth. They are, moreover, the essence of the very existence of cities. One can thus relate the growth of cities to economies of scale - and hence consider them agglomeration economies, thereby putting to test the theories of economic growth.

This article aims to add new methodological procedures that broaden the interpretation spectrum for specialized productive agglomerations in order to identify the economies of scale present in local productive sectors. Furthermore, this paper proposes investigating the relationship between the local economic structure and the local productivity level. To do so, we analyze local industrial wage levels. The geographical dimensions considered are that of Brazilian micro-regions.

Thus, local productivity is influenced not only by personal productive characteristics, such as elements related to human capital, regional attributes, features that impact upon industrial productivity differential or differences in regional productive structures. It is, on the other hand, also influenced by urban attributes - identified here as centrality and the availability of complex services.

Recently, empirical research on agglomeration economies has shown undeniable progress, especially due to improvements in the quality of available data. In spite of these efforts, however, the literature on the issue is still inconclusive, and there is thus room for new estimations. Furthermore, much of the empirical literature uses data from developed countries, despite the fact that the role of the local economic environments differs from country to country. A series of works in this vein exists in Brazil. It is nevertheless the case that this sort of approach, conducted on a nationwide basis and especially when highlighting urban attributes, is still very incipient. Thus, the present work, usually applied to developed countries, is expected to contribute to the increasing research on developing regions.

In addition to this introduction and the conclusion, this paper has three sections. Section 2 deals with the theoretical framework that supports the development of this work. Section 3 addresses the methodology and discusses the econometric model and the database used in this research. Finally, section 4 analyzes the results.

\section{$2.0 \quad$ Literature review}

The literature on agglomeration economies relates the growth of industrial activity to the increased productivity of firms -which arises from external economies of scale according to the productive structure of the region. For Marshall (1980), these scale externalities derive from specialization in industrial activity. They can be synthesized in the known Marshallian triad: the suppliers-users intersectoral linkage effects, which generate pecuniary external economies - that is, the advantages associated with the use of inputs common to all firms (input sharing); the effects of inter-firm technological knowledge spillovers, which generate technological external economies; and the gains from having centers of specialized workers, which can bring about both pecuniary and technological external economies (labor market pooling).

As for Jacobs (1969), the largest and most important source of externalities is the diversity of economic activities in cities. The wide range of goods, services, technologies and tacit knowledge found in a diverse urban center spurs a "cross fertilization of ideas". Innovations arise from this fertilization of ideas that circulate between the various economic activities present in a same city. This, in turn, enables the development of new types of work and novel occupations, hence increasing the capacity to produce new goods and services. In this case, it is important to emphasize that the benefits from agglomeration are not restricted to the realms of production, but also extend to consumption (Lemos, Crocco and Santos, 2005). Big cities offer a greater variety of consumer goods and public services as well as a greater possibility of social contact, which would result in externalities. Thus, large cities also become attractive to workers/consumers. 
A recent theory attributes the spatial agglomeration of industry to increasing returns to scale in production. Henderson (1974) suggests that agglomeration economies result from positive spillovers between firms that share the same location. Although firms are perfectly competitive and assume the existence of constant returns to scale, the agglomeration of economic activity generates externalities that increase the productivity of all firms in a particular industry in a particular geographic location -à la Marshall. To relate human capital spillovers to spatial agglomeration, Black and Henderson (1999) combined elements from Lucas (1988), Henderson (1974) and Eaton and Eckstein (1997). They built a dynamic model of city formation where there are economies external to the industry and human capital externalities in a given specific location. The industrial agglomeration makes all firms, within the same local industry, more productive, while the agglomeration of workers makes all local workers, regardless of their industry, more productive.

On the other hand, Krugman (1991) suggests that industrial agglomeration results from demand linkages between firms, which are created by the interaction of transportation costs and fixed production costs. In this case, economies of scale are internal, rather than external, and there are transport costs for shipping goods between regions. The basic model resembles that of international trade theory ${ }^{1}$, complemented by a regional scenario. Individuals prefer to consume the widest possible variety of products, but the fixed cost of production limits the number of goods that can be produced. In response to the consumer preference for variety, firms differentiate their product, which leads to monopolistic competition. Given the fixed costs of production, companies prefer to concentrate production in a single location and, given transportation costs, firms prefer to locate their plants near large markets. The possibility of meeting a large local market via a single plant with low shipping costs attracts companies to densely concentrated areas.

At first, the Henderson models of external economies and the Krugman models of regional demand linkages seem to have similar implications for the spatial distribution of economic activity. Both predict that the spatial distribution will be uneven and that the nominal wages and housing prices across regions will be positively correlated with the agglomeration of economic activity. The models differ, however, as to how agglomeration occurs. In the original Henderson model (1974), agglomeration occurs because companies benefit from being close to another company in the same industry. In Black and Henderson (1999), an additional motivation for agglomeration is that workers benefit from being close to other workers. In Krugman (1991), agglomeration occurs because firms benefit from being close to large consumer and industrial markets. Among the precursor works that approach externalities that way, undoubtedly those of Gleaser et al. (1992) and Henderson et al. (1995) were the most influential. They made it possible to use well-defined theoretical arguments to distinguish between the effects of diversity and sectoral specialization, as well as between the effects of monopoly and local competition, as purveyors of knowledge spillovers -which would reflect in the growth of industries and regions.

Gleaser et al. (1992) were pioneers in formalizing the three main theoretical arguments that gave consistency to the dynamic externalities approach: the theoretical propositions of Marshall (1890), Arrow (1962) and Romer (1986), or the Marshall-Arrow-Romer model (MAR externalities); the theoretical proposition based on the arguments of Jacobs (1969) - Jacobs externalities; and the theory of Porter (1990), which leads to Porter externalities. These three theories are not always mutually exclusive, but have different visions as to the kind of externality that would be more important for growth. Anyway, these growth models have knowledge spillovers as the main source of externalities. Thus, among the main reasons for local growth is the interaction between agents that capture bits of knowledge from each other without paying for it. These externalities occur both within sectors and between sectors. According to Gleaser et al. (1992), the theories of externalities are extremely attractive because they attempt to explain both city formation and growth. In these authors' view, agglomeration economies are based on technological spillovers and mainly explain urban growth. They are, additionally, also relevant to elucidate the industrial location pattern of cities - the degree to which they are diversified and specialized.

Finally, the pattern of externalities is linked to some aspects of urban development, such as the attractiveness of different centers to different productive sectors. If an industry is mainly subject to location economies, its firms tend to agglomerate predominantly in cities that are highly specialized in this activity or in directly interconnected activities. The urban specialization, in this case, will allow firms to fully exploit externalities without being subject to excessively high costs of congestion. For example, traditional and labor-intensive industries are often located in mono-industrial, medium-sized cities. On the other hand, if urbanization economies are more relevant for an activity, it will primarily develop in large cities with a highly diversified economy. Thus, technology-intensive industries and financial services, for example, generally are relatively concentrated in urban centers (Henderson, 2003).

\subsection{The model}

${ }^{1}$ See Krugman (1980). 
Productivity is influenced by personal production characteristics - i.e., elements related to human resources. It is also influenced by regional attributes, features which impact industrial productivity differentials, differences in the regional production structure production and, finally, urban attributes such as centrality and the availability of complex services. This article intends to focus on the performance of three dimensions as regards their impact on the regional productivity gap. The first is the externalities - location/MAR, urbanization/Jacobs and Porter. The second is the performance of diversified urban centers. The third is the industrial particularities of each industrial segment.

Studying agglomeration economies through urban wage differentials can be considered one of the most recent approaches in the literature. Economic theory assumes that, in competitive markets, workers are paid according to the value of their marginal product. Although this hypothesis seems restrictive, the approach does not appear unviable if we relax the assumption. Even in the absence of perfect competition, salaries tend to be higher in areas of relatively high productivity (Rosenthal and Strange, 2004). While several theories advocate raising the productivity of firms with the concentration of economic activities, indirectly investigating the variation in productivity through wages seems feasible.

We present here an estimable equation that indirectly captures the effects of agglomeration on productivity, via wage levels. The starting point for our empirical research follows the work of Combes et al., (2008). The authors investigated the determinants of wage differentials in local labor markets in France, arguing that there are three major explanations for the spatial income gap.

The first explanation assumes that spatial differences in wages are directly reflected by spatial differences in the composition of the workforce and the skills. The second explanation is based on local endowments of attributes that are external to the employees. The third explanation attributes the central role in the spatial differentiation of productivity gains - and hence wages - to interactions in the labor market. The most important contribution of Combes et al. (2008) is the assumption that all three sources are relevant in explaining the spatial differences of wages -particularly as they include all of them in a single model, thus allowing for the analysis of the relative importance of each.

Combes et al. (2008) built their model based on the profit equation of a representative firm for a competitive area $a$, industry $k$ and in year $t$.

$$
\pi_{a, k, t}=p_{a, k, t} y_{a, k, t}-\sum_{i \in(a, k, t)} w_{i, t} l_{i, t}-r_{a, k, t} z_{a, k, t}
$$

Where, $p_{a, k, t}$ is the price of the product $y_{a, k, t} ; w_{i, l}$, and $l_{i, l}$ are the salary per day and the number of working days, respectively, for each employee at firm $i$ in year $t, z_{a, k, t}$ represents other production factors and $r_{a, k, t}$ the prices. The product follows a Cobb-Douglas function:

$$
y_{a, k, t}=A_{a, k, t}\left(\sum_{i \in(a, k, t)} s_{i, t} l_{i, t}\right)^{b}\left(z_{a, k, t}\right)^{1-b}
$$

in which: the coefficient $b$ is such that $0<b \leq 1 ; s_{i, t}$ denotes the ability of the worker $i$ in year $t$, and $A_{a, k, t}$ is the total factor productivity in $(a, k, t)$. If, in competitive equilibrium, the worker receives wages equal to their marginal product, then:

$$
w_{i, t}=b p_{a(i, t) k(i, t) t} A_{a(i, t) k(i, t) t}\left(\frac{z_{a(i, t) k(i, t) t}}{\sum_{i \in(a, k, t)} s_{i, t} l_{i, t}}\right)^{1-b} s_{i, t}
$$

Applying the first order condition for profit maximization with respect to other factors and inserting the result in Eq. (03), we have:

$$
\begin{aligned}
& w_{i, t}=b(1-b)^{1-b / b}\left(p_{a(i, t) k(i, t) t} \frac{A_{a(i, t) k(i, t) t}}{\left(r_{a(i, t) k(i, t) t}\right)^{1-b}}\right)^{1 / b} s_{i, t} \\
& w_{i, t}=B_{a(i, t) k(i, t) t} s_{i, t}
\end{aligned}
$$


This result shows that wage differentials between regions may reflect differences in the abilities of individuals or, alternatively, may reflect differences in productivity caused by local capital endowment sand interactions. In equation (04), the ability is captured by $s_{i, t}$, and the other two explanations will enter the term $B_{a(i, t), k(i, t) f}$.

To make the model estimable from available data, Combes et al. (2008) made two assumptions. The first is that the ability of the worker $i$ is given by:

$$
\log \mathbf{g}_{i, t}=X_{i, t} \varphi+\delta_{i}+\varepsilon_{i, t}
$$

Where, $X_{i, t}$ is a vector of the characteristics of workers; $\delta_{i}$ is a vector of the fixed effects for the worker; $\varepsilon_{i, t}$ is the i.i.d. error term.

The second one considers $B_{a(i, t), k(i, t) \neq}$ as given by:

$$
\log B_{a(i, t) k(i, t) t,}=\beta_{a, t}+\mu_{k, t}+I_{a, k, t} \gamma_{k}
$$

in which: $\beta_{a, t}$ is a vector of fixed effects indicating the area and year; $\mu_{k, t}$ is a vector of fixed effects indicating the industry and year; $\gamma_{k}$ is a vector of associated coefficients and $I_{a, k, t}$ is a vector of variable interactions within the industry for each area/industry/year.

Taking the log of equation (04) and combining it with equations (05) and (06) we have:

$$
\log \left(v_{i, t}\right)=\beta_{a(i, t) t,}+\mu_{k(i, t)}+I_{a(i, t) k(i, t) t} \gamma_{k(i, t)}+X_{i, t} \varphi+\delta_{i}+\varepsilon_{i, t}
$$

Equation (07) is the inverse labor demand equation. This model takes the log of the wage rate of workers as a function of observable $\left(X_{i, t}\right)$ and unobservable $\left(\delta_{i}\right)$ characteristics, the fixed effects of their geographical area $\left(\beta_{a(i, t), t}\right)$ and sector $\left(\mu_{k(i, t)}\right)$ and local characteristics of the sector in which they are employed: relative participation in the local economy, the number of establishments and the relative share of workers in professional occupations.

This estimation allows for separately measuring the personal and area effects. One can thus assess the relative importance of skills, local endowments and interactions (agglomeration economies) for wage differentials in space. Therefore, Combes et al. (2008) adopt as their identification strategy a two-stage estimation. They first estimate equation (07), from which is obtained the vector of fixed effects by area, $\left(\beta_{a(i, t), t}\right)$. They then regress the latter on variables representing the local endowments and intersectoral interactions. The specification takes the following form:

$$
\beta_{a, t}=\varpi_{0}+\theta_{t}+I_{a, t} \gamma+E_{a, t} \alpha+v_{a, t}
$$

In this equation, $\theta_{t}$ are time fixed effects; $\gamma$ is the vector of coefficients associated with the local intersectoral interactions $I_{a, t} ; \alpha$ is a vector of coefficients associated with local capital endowments $E_{a, t}$; and $v_{a, t}$ is the i.i.d. error term that reflects local technological shocks.

Combes et al (2008) also show that the model presented by equation (07) can be aggregated and estimated for the geographical area. Thus, equation (07) can be rewritten as:

$$
\log w_{a, k, t}=\beta_{a, t}+\mu_{k, t}+I_{a, k, t} \gamma_{k}+\varsigma_{a, t} \phi_{a, t}+\varepsilon_{a, t}
$$

Where, $\log w_{a, k, t}$ is the average $\log$ of the wages of individuals in an industry $k$, in a given region $a$, in year $t ; \phi_{a, t}$ is a vector of coefficients associated with $\varsigma_{a, t}=X_{a, t} \varphi+\delta_{a}$, which is a vector that captures the level of human capital in area $a$ - or, as we would rather call it, the average skill level of workers in area $a$.

In the first stage, information is available at the individual level; in the second, at the level of the area or region of study. Aggregating the equation in the first stage allows us to estimate a model with information from only the level 
of the area, which is appropriate for the database available for this work. Thus, substituting Eq. (08) into Eq. (09), we have:

$$
\log v_{a, k, t}=\varpi_{0}+\theta_{t}+I_{a, t} \gamma+E_{a, t} \alpha+\mu_{k, t}+I_{a, k, t} \gamma_{k}+\varsigma_{a, t} \phi_{a, t}+\varepsilon_{a, t}+v_{a, t}
$$

There is a problem in the aggregation of equation (09).The variable $\log w_{a, k, t}$ represents the average of the $\log$ of the wages of each individual $I$ of an industry $k$, given region $a$. This becomes a problem because our database has no information on the individual level to measure the average. However, without loss of generality, the log of the mean wage is a good proxy for the average $\log$ of wages. We thus carry out the estimation with this proxy, since we have the average salary of an industry $k$, given a region $a$.

Another important issue is that the estimates are made separately for each segment ${ }^{2}$. One can then change the equation (10) once more. First, the subscript $k$ may be removed. Then the $\mu_{k, t}$ that captures the fixed effects for each industry and time period can also be deleted. Moreover, $\varepsilon_{a, t}$ and $v_{a, t}$ are i.i.d. error terms, and we can therefore define $\xi_{a, t}$ as $\xi_{a, t}=\varepsilon_{a, t}+v_{a, t}$. The variable $E_{a, t}$ that captures the effects of local endowments may be included in the variable $\theta_{t}$, which captures time fixed effects, thereby forming a component of fixed effects indicating the area and time. The equation can then be expressed as follows:

$\log w_{a, t}=\varpi+\theta_{a, t}+I_{a, t} \gamma+\varsigma_{a, t} \phi+\xi_{a, t}$

where: $\log w_{a, t}$ is the $\log$ of the mean wage in a given industry in the region $a$ in year $t, \theta_{a, t}$ are fixed effects for area/year; $I_{a, t}$ captures the effects of the economic structure in an area in year $t, \varsigma_{a, t}$ captures the effects of the average skill of workers in the region $a$ in year $t, \xi_{a, t}$ is the error term that reflects the local technological shocks and are assumed to be and i.i.d. for regions and periods.

The urban problematic that Lemos (1988) cites can be considered in two fundamental aspects. The first is that the process of capital accumulation engenders a movement of urbanization that leads to the transfer of activities and people from rural areas to the city ${ }^{3}$. The second aspect is that the tendency for urban centralization occurs in parallel with the above concentration. Basically, centralization is the uneven development of urban centers, which implicates the relative concentration of economic activities in urban centers (Lemos, 1988).

Hence, one can derive two fundamental characteristics of diverse urban centers. The first shows that the process of urban concentration implicates the relative concentration of economic activities, which we will herein call the relative concentration of modern services. The second results in uneven interregional development, which implies the centralization of economic activities in urban centers or in certain polarized regions of the country.

In this sense, we find two diversified features in urban centers: one is centrality and the other is the availability of complex services. However, variable $\theta_{a, t}$ captures the fixed effects for area/year. We will break it down as follows:

$$
\theta_{a, t}=C_{a}+S_{a, t}+\tau_{a, t}
$$

Where, $C_{a}$ is a variable to capture centrality; $S_{a, t}$ is a variable to capture the concentration of modern services; and $\tau_{a, t}$ is an i.i.d. error term for other unobserved regional influences. Thus, substituting Eq. (12) into Eq. (11) and making $e_{a, t}=\tau_{a, t}+\xi_{a, t}$, we have the equation estimated in this article:

\section{Externalities}

2The studied segments are Low-Technology, Medium-Low-Technology, Medium-High-Technology and High-Technology.

${ }^{3}$ Lemos (1988) mentions that is important to make a distinction between cities and urban centers. The concept of a city involves geographical and population-related city aspects, while that of urban centers or of urbanization refers to a process of developing complex services. 


$$
\log w_{a, t}=\varpi+\underbrace{C_{a}+S_{a, t}}+l_{a, t} \gamma+\underbrace{S_{a, t} \phi+e_{a, t}}
$$

Diversified Urban Centers

Human Capital

Another issue that deserves attention regards the wage differential between regions that offsets the differences in cost of living and amenities (Topel, 1994, Menezes and Azzoni, 2006). We must also consider, as a control, the different cost of living in the various regions, as they influence the pay gap in between them. We thus attempt to deal with this potential bias by using temporally constant monetary values that are, moreover, regionally adjusted ${ }^{4}$ to account for spatial differences in the cost of living.

Spatial spillover effects capture the influence of neighboring localities in the development of a particular locality. Anselin (2003) argues that the inclusion of spatial effects is important from an econometric point of view. If the underlying data triggers processes that include a spatial dimension, but this is omitted, then the estimations may lead to inconsistent estimators.

This implies that the evolution of productivity in a particular region, for example, can be influenced by the evolution of productivity in neighboring regions, via spatial externalities. The existence or non-existence of these effects can be determined by a set of techniques that have been developed by spatial econometrics. However, the distance between economic agents influences the productivity gains derived from economies of scale. Evidence for Brazil and the United States indicates that, by doubling the distance to a regional center, the profits can be reduced up to $6 \%$ (Henderson, 1994). In this context, the concept of distance can be generalized to distance in physical space and in industrial space. For example, spillovers between industries are more likely if the latter share related production technologies, and are hence closer in industrial space (Audetsch and Feldman, 1999). In addition, the extent to which agglomeration economies attenuate distance is different for the various types of agglomeration. For example, knowledge spillovers that rely on face-to-face communication will decay more rapidly with distance than the effects of the domestic market (Venables, 2006).

In this regard, as we work with a high level of geographic aggregation, it makes no sense here to control for spatial spillover effects with techniques such as spatial econometrics. As an example, Melo and Simões (2011) used the same aggregation that we adopted in this study and found no evidence of spillovers to study spatial data in the Brazilian Northeast. We believe that this pattern will repeat itself if the study is replicated throughout the country, given that the high level of aggregation adopted (micro-regions) mitigates the effects of spillovers. Having said that, studies with a lower level of aggregation, such as Gallinari (2006), found evidence of spatial spillovers. Therefore, due to the fact that we used a high geographical aggregation in this work, we will not use spatial econometric techniques, for the large distances concerned mitigate the spatial spillover effects.

\subsection{The materials}

This study will be based primarily on information produced by the Secretariat of Policies for Employment and Wages of the Ministry of Labor and Employment (MTE).For the construction of the indicators that we will use in the empirical part of the work, we use data from the Annual Listing of Social Information (RAIS) for the period from 2000 to 2010.

For the division of the manufacturing sectors, we used the technological intensity classification of the Organization for Economic Cooperation and Development (OECD) (Hatzichronoglow, 1997). It employs the Research and Development (R\&D) intensity indicator, a ratio obtained by dividing R\&D expenditures by value added or output, to classify the sectors into four groups: high-technology, medium-high-technology, medium-low-technology and lowtechnology. Frame 1 shows the divisions of the National Classification of Economic Activities - version 1.0 (CNAE 1.0) - for the manufacturing industry, classified according to the degree of technological intensity. By using this classification, we intend to identify how the industrial particularities influence the local level of productivity. We also intend to capture the differences between segments determined by the productive structure of the region.

Frame 1 - OECD classification of technological intensity

${ }^{4}$ See the attachment for the calculation of regionalized real wages. 


\begin{tabular}{|c|c|}
\hline Low Intensity & $15 ; 16 ; 17 ; 18 ; 19 ; 20 ; 21 ; 22 ; 26 ; 27 ; 28 ; 36 ; 37$ \\
\hline Medium-Low Intensity & $23 ; 24 ; 25$ \\
\hline High Average Intensity & $29 ; 30 ; 33 ; 34$ \\
\hline High Intensity & $31 ; 32 ; 35$ \\
\hline
\end{tabular}

Source: Adapted from Furtado and Carvalho, 2005 and from Hatzichronoglou (1997)

As the geographical unit of analysis, we use the Brazilian micro-regions. The Brazilian Institute of Geography and Statistics (IBGE, 1990) defines them by grouping municipalities according to economic and social similarities. As to the information about centrality, we draw them from the Study of the Territorial Dimension of Planning (Volume III: Reference Regions), organized by the Ministry of Planning, Budget and Management (MP, 2008).

\subsection{Description of variables}

To capture the effects of the economic structure that impact the forces of agglomeration, we follow the literature (Glaeser et al. 1992; Ciccone e Hall, 1996; Combes, 2000; Glaeser e Mare, 2001; Combes et al, 2008) and use indicators representative of specialization, diversity, size of the local economy, competition in the segment and in the micro-region, and an indicator for the level of local craftsmanship.

We will consider the location quotient as a proxy for industrial specialization and for the source of location/MAR externalities. It is also used by Gleaser et al. (1992) and Combes (2000). In Combes (2000), the diversity indicator used is obtained via the modified Hirschman-Herfindahl index of sectoral concentration, based on the participation of all sectors except for the one at hand. According to Gleaser et al. (1992), Henderson et al. (1995) and Combes (2000), a positive relationship between industrial diversity and productivity, measured in terms of wage levels, can be seen as evidence of the presence of urbanization/Jacobs externalities.

As an indicator of competition, the decision was to use the measure based on Gleaser et al. (1992) with minor adaptations. In order to better capture the effect of competitive markets, this paper uses employment information from firms with fewer than 100 employees. This small modification as well as Ò hUallacháin and Satterthwite (1992) seeks to better distinguish firms more likely to be in a competitive market -that is, micro and small enterprises (MSEs), defined based on the number of workers ${ }^{5}$. Similarly, Rosenthal and Strange (2003) use information from establishments with fewer than 25 employees to test the effects of agglomeration economies on productivity. If their relationship with the wage rate in the industry is positive, then it means that a higher level of competition potentiates externalities. In this case, such externalities are in accordance with the Porter theories. Otherwise, if the relationship with the industrial wages rate is negative, there is evidence of location/MAR externalities - namely, that the monopoly structure tends to provide better results.

The total employment density index reflects the size of the local economy and is relevant to capture the differences between the analyzed regions. It helps explain whether local factors have an influence on the growth of employment and the wage rate, regardless of sectoral factors. The density indicator expresses the size of the local economy and can also influence the intensity with which both sets of agglomeration forces act. As to market forces, the size of the market has an effect on location choices for the firm, especially in the presence of transportation costs. The size of the local economy can also foster the presence of pure positive externalities, such as public goods, and pure negative externalities, such as pollution and traffic congestion (Combes, 2000).

To address this issue, Combes (2000) uses the total employment of the period in question normalized by the total area of each region, measured in square kilometers. This way of making its participation relative seems better suited for comparing the indicator across regions than the absolute form.

We built the proxy indicator for centrality by taking a dummy for the micro-regions identified as Sub-poles in the Study of the Territorial Dimension of Planning (Volume III: Regions Reference). This study, organized by the Ministry of Planning, Budget and Management (MP, 2008), regionalized the Brazilian territory according to two scales (macro-regional and sub-regional). This study identified 118 sub-regions associated to the micro-regions, which allows for a finer adjustment between economic indicators and social polarization. It also provides greater compatibility with environmental characteristics and cultural identity. Our dummy was constructed from these subpoles. The name of each sub-pole is that of the most important micro-region in the sub-pole, which enabled us to identify the micro-regions to construct the dummy. Thus, the centrality dummy assumes value "one" for the microregions witha sub-pole name and "zero" otherwise.

\footnotetext{
${ }^{5}$ SEBRAE classifies the size of the companies according to the number of workers employed. This classification is as follows: up to 19 employees - Microenterprise; 20-99 employees - Small Company; 100-499 employees - Medium Enterprise, more than 500 employees - Large Company.
} 


$$
C_{a}=\left\{\begin{array}{l}
1=\text { for the micro regions that name the sub - pole } \\
0=\text { para as demais microrregi ões }
\end{array}\right.
$$

The variable concentration of modern services was built by calculating the Locational Quotient (LQ) for modern services sectors (see Annex). We then calculated the average of the LQs for each state in the country. Having done so, we identified which micro-region shad a LQ for modern services higher than the average of its state. After this, we created a dummy variable that assumes value "one" for the micro regions with a LQ for modern services higher than the state average and "zero" otherwise.

$$
S_{a, t}=\left\{\begin{array}{l}
1=\text { mi crnegi onst hashowed LQ moder ser vi ces than t beat aver ag } \\
0=\text { for } \text { thet hemi cro }
\end{array}\right.
$$

The indicator used as a proxy for the local skill level is described as:

$$
e d u c_{m, t}=\frac{\operatorname{grad}_{m, t}}{e m p_{m, t}}
$$

Where, grad $_{m, t}$ is the number of graduates working in micro-region $m$ in period $t$.

Having presented our identification strategy, the variables used and our database, we now begin to present the estimation results in the next section. The estimations were carried out for all the regions in Brazil, from 2000 to2010, for the segments classified as Low-, Medium-Low-, Medium-High- and High-Technology.

\subsection{Results and discussions}

The basic hypothesis of this study is that local productivity, measured by the average local wage, is influenced not only by personal productive characteristics, but also by regional attributes, by industrial particularities that impact the productivity gap, by differences in the regional productive structures and, finally, by urban attributes such as centrality and the availability of complex services.

The model specified in equation (13) was estimated for each segment by an unbalanced panel with fixed effects ${ }^{6}$, all of them corrected with heteroskedasticity-robust standard errors. The estimation results reveal the elasticity of the economic structure variables in relation to the wage level. That is, they indicate the percentual variations in the endogenous variable, ceteris paribus, given a $1 \%$ decrease in any given explanatory variable (when their coefficient is negative). Each regression has at least two explanatory variables significant at $1 \%$. The used model seems to have adjusted well to the sectors, given that the values of the adjusted $-\mathrm{R}^{2}$ were 0.57 on average.

The results of the regression analysis for the four segments are shown in Table 1. As expected, the variables that indicate specialization, $q l$, and industry diversity, div, showed positive and statistically significant results in all estimations. Despite the simplification of the model, there is evidence of local externalities influencing wage levels, thus highlighting the positive location/MAR and urbanization/Jacobs externalities.

The proxies for human capital, educ, and the size of the local economy, den, also showed statistically significant results in all segments. The coefficient signs were positive, which, in the first place, reaffirms the importance of the level of local human capital to increase productivity - and thus lead to higher salaries than in regions with lower human capital levels. In the second place, it shows that the size of the local economy is important to grasp the differences between the analyzed regions. This reveals that the size of the market has a positive effect on the location choices of firms, especially in the presence of transportation costs.

It is interesting to note that the coefficients of the variables educ and den are higher as the technology level of the segment increases. That is, the more intensive in technology is segment, the greater will be the impact of the local average skill level. Likewise, the influence of the size of the local economy on the level of productivity and wages will also be higher. Regarding the indicator of competition, comp, the estimates are significant, but the results showed negative signs. This indicates that it is not a competitive structure that spurs productivity, but rather a monopolistic structure, à la Marshall. That is, there is no evidence of Porter externalities for the industrial production structure of the Brazilian micro-regions. However, one should take into account that the data structure

${ }^{6}$ We conducted a Hausman Specification Test, the result pointed Fixed Effects specification as appropriate for the model. 
used in this research does not include factors such as the level and type of previously installed capital or the production levels of individual firms.

Table 01: Estimation of the model (13) using as dependent variable regionalized real wages

\begin{tabular}{|c|c|c|c|c|c|c|c|c|c|c|c|}
\hline Segments & const & $q \mathrm{q}$ & div & comp & den & educ & d_centralities & d_serv_modern & R2-adjust & $\mathrm{F}$ & $\mathrm{N}$ \\
\hline $\begin{array}{l}\text { Low } \\
\text { Technology }\end{array}$ & $\begin{array}{c}5,968 \\
(0.034)^{* \star *}\end{array}$ & $\begin{array}{c}0,121 \\
(0.005)^{\star \star \star}\end{array}$ & $\begin{array}{c}0,072 \\
(0.005)^{\star \star \star}\end{array}$ & $\begin{array}{c}-0,241 \\
(0.008)^{\star \star \star}\end{array}$ & $\begin{array}{c}0,048 \\
(0.003)^{\star \star *}\end{array}$ & $\begin{array}{c}0,032 \\
(0.010)^{\star \star \star}\end{array}$ & $\begin{array}{c}0,071 \\
(0.008)^{\star * \star}\end{array}$ & $\begin{array}{c}0,011 \\
(0.007)\end{array}$ & 0,62 & 497,66 & 6.084 \\
\hline $\begin{array}{l}\text { Medium-Low } \\
\text { Technology }\end{array}$ & $\begin{array}{c}6,424 \\
(0.063)^{\star \star \star}\end{array}$ & $\begin{array}{c}0,146 \\
(0.006)^{\star \star \star}\end{array}$ & $\begin{array}{c}0,127 \\
(0.017)^{\star \star \star}\end{array}$ & $\begin{array}{c}-0,139 \\
(0.012)^{\star \star *}\end{array}$ & $\begin{array}{c}0,084 \\
(0.006)^{\star * \star}\end{array}$ & $\begin{array}{c}0,104 \\
(0.018)^{\star * \star}\end{array}$ & $\begin{array}{c}0,057 \\
(0.015)^{\star \star \star}\end{array}$ & $\begin{array}{c}0,007 \\
(0.012)\end{array}$ & 0,47 & 214,40 & 4.854 \\
\hline $\begin{array}{l}\text { Medium-High } \\
\text { Technology }\end{array}$ & $\begin{array}{c}6,280 \\
(0.052)^{\star \star \star}\end{array}$ & $\begin{array}{c}0,191 \\
(0.006)^{\star \star \star}\end{array}$ & $\begin{array}{c}0,075 \\
(0.021)^{\star \star \star}\end{array}$ & $\begin{array}{c}-0,159 \\
(0.011)^{\star \star \star}\end{array}$ & $\begin{array}{c}0,083 \\
(0.005)^{\star * *}\end{array}$ & $\begin{array}{c}0,134 \\
(0.016)^{\star \star \star}\end{array}$ & $\begin{array}{c}0,020 \\
(0.013)\end{array}$ & $\begin{array}{c}0,017 \\
(0.010)^{*}\end{array}$ & 0,63 & 362,42 & 4.438 \\
\hline $\begin{array}{l}\text { High } \\
\text { Technology }\end{array}$ & $\begin{array}{c}6,409 \\
(0.069)^{\star * *}\end{array}$ & $\begin{array}{c}0,152 \\
(0.005)^{\star * *}\end{array}$ & $\begin{array}{c}0,122 \\
(0.017)^{\star \star *}\end{array}$ & $\begin{array}{c}-0,070 \\
(0.011)^{\star * *}\end{array}$ & $\begin{array}{c}0,092 \\
(0.005)^{* * *}\end{array}$ & $\begin{array}{c}0,287 \\
(0.020)^{\star * *}\end{array}$ & $\begin{array}{c}0,007 \\
(0.012)\end{array}$ & $\begin{array}{c}0,027 \\
(0.013)^{\star \star}\end{array}$ & 0,57 & 176,26 & 3.345 \\
\hline
\end{tabular}

Note: The standard error of each estimate is between brackets, ${ }^{*}$ significant at $10 \%$; ${ }^{* *}$ significant at $5 \%,{ }^{* * *}$ significant at $1 \%$.

The identification strategy in this paper to capture the influence of diversified urban centers on local productivity uses dummies as proxies for attributes of urban scale attributes, one for centrality and one for the concentration of modern services. The dummy for centrality presented statistically significant and positive values in the segments of Low- and Medium-Low-Technology. With respect to the segments of Medium-High- and High-Technology, the results showed positive signs that were not, however, significant.

The dummy for the concentration of modern services showed significant results and positive coefficients for the segments of Medium-High- and High-Technology. However, despite the positive coefficients for the segments of Low- and Medium-Low-Technology, neither showed statistically significant results.

In our definition, a micro-region that displays centrality and a relative concentration of modern services is characterized as a diverse urban center. The influence of these diverse urban centers on productivity should be observed if the dummies assume unit value. The results show that, in the segments of Medium-High- and HighTechnology, diverse urban centers have a positive impact on productivity, which is not the case in the Medium-Low and Low segments. The pattern of externalities is linked to some aspects of urban development, such as the attractiveness of different centers to the various productive sectors. These results show that certain industries, namely segments of Medium-Low- and Low-Technology, are subject advantages when located in a region of some centrality. That is, traditional industries tend to gain more advantages in highly specialized cities than in large, diversified urban centers.

On the other hand, Jacobs (1969) argues that urban characteristics related to the productive efficiency of traditional industries, such as sectoral specialization, are not correlated, in general, to the factors behind the development of innovative activities. Thus, intermediate-sized urban centers specialized in a few industrial activities can display high efficiency in these sectors - but, they do not, in general, stand out as innovation centers. Therefore, the centrality indicator was not significant for the segments of Medium-High- and High-Technology. If an activity is subject more to urbanization economies, it will primarily develop in large-scale cities and highly diversified economies. Thus, technology-intensive industries and financial services are, in general, relatively concentrated in urban centers, for the latter provide them diverse advantages that increase their productivity.

\subsection{Conclusion and policy implications}

This work intended to analyze the determinants of productivity differentials between Brazilian micro-regions from 2000 to 2010. Our central hypothesis is that local productivity, measured by the average local wage, is influenced not only by personal productive characteristics, but also by regional attributes, by industrial particularities that impact the productivity gap, by differences in the regional productive structures and, finally, by urban attributes such as centrality and the availability of complex services.

The investigation of the effects of increasing returns to scale on industrial productivity was indirectly held through wage equations. There are some alternative arguments in the literature that aim to explain the occurrence of wage disparities between regions. Among these arguments, we highlighted those related to wage differentials that offset the higher costs of living and of local amenities (Topel, 1994; Azzoni and Menezes, 2006) and the wage gap resulting from inter-regional differences in the allocation of human capital (Lucas, 1988; Wheaton and Lewis, 2002). Our model also took these two factors into account.

Regarding the results, we first observe that there are evidences of the presence of location/MAR externalities in all segments. This finding can be seen in the specialization indicators and in the negative result found for the 
competition indicator. There is still evidence of urbanization/Jacobs externalities in all sectors, but the results were most intense in the segments of Medium-High- and High-Technology. However, we found no evidence of Porter externalities.

The results for urban attributes indicate that diversified urban centers did not influence the increase in productivity in the segments of Low- and Medium-Low-Technology. The pattern of externalities is linked to some aspects of urban development, such as the attractiveness of different centers for the various productive sectors. Thus, our results showed that certain industries enjoy benefits if they are located in a region of some centrality. In this study, for example, industries in the Low- and Medium-Low-Technology segments tend, in general, to obtain advantages in these areas, which display a low degree of diversification.

On the other hand, some activities are more likely to develop economies of urbanization in large-scale cities and highly diversified economies. Thus, technology-intensive industries and financial services industries, such as those of Medium-High- and High-Technology, are, in general, relatively concentrated in diversified urban centers, for they therein enjoy advantages that increase their productivity. In this case, the productive efficiency of the most dynamic industries is not, on average, correlated to intermediate-sized urban centers specialized in a few industrial activities. Therefore, the indicator of centrality was not significant for the segments of Medium-High- and HighTechnology. These industries gain in productivity only in diversified urban centers, not in medium-sized centers.

Finally, it is worth noting that these results are in line with most studies on the subject, which show evidence of local externalities. However, the subject has a relatively high level of complexity, which indicates the need for further empirical investigations. Furthermore, the study may be extended to new levels of development by including new approaches, adding new methods and expanding the database.

\section{References}

Audretsch, D. B.; Feldman, M. 1996. R\&D spillovers and the geography of innovation and production, American Economic Review 86(4), p. 253-273.

Anselin, L. 2003. Spatial Externalities, Spatial Multipliers and Spatial Econometrics. International Regional Science Review, v.26, n.2, p.153-166.

Arrow, K.J. 1962. The economic implications of learning by doing. Review of Economic Studies, v. 29, n.3, p.155-173.

Beaudry, C., Schiffauerova, A. 2009. Who's right, Marshall or Jacobs? The localization versus urbanization debate. Research Policy 38, p. 318-337.

Black, D.; Henderson, J.V. 1999. A Theory of Urban Growth. Journal of Political Economy107: 252-284.

Boschma, R.. Iammarino,S. 2009. Related Variety,Trade Linkages, and Regional Growth in Italy. Economic Geography, vol. 85, n. 3 pp. 289-311.

Ciccone, A., Hall, R.E. 1996. Productivity and the density of economic activity. American Economic Review, v.86, n.1, p.54-70.

Combes, P.P. Economic structure and local growth: France, 1984-1993. Journal of Urban Economics, v. 47, p. 329355. 2000.

Combes, P.P.; Duranton, T.; Gobillon, J.M.. 2008. Spatial wage disparities: Sorting matters! Journal of Urban Economics.v.63, n.2, p.723-742.

Eaton, J.; Eckstein, Z. 1997. Cities and Growth: Theory and Evidence from France and Japan. Regional Science and Urban Economics.v.27, p.443-474.

Feldman, M.P.; Audretsch, D.B. 1999. Innovation in cities: Science-based diversity, specialization and localized competition. European Economic Review, v.43, n.2, p.409-429.

Fontes, G,G. 2006. Atributos urbanos e diferenciais regionais de salário no Brasil, 1991 e 2000. Dissertação (Mestrado) - Centro de Desenvolvimento e Planejamento Regional, Universidade Federal de Minas Gerais, Belo Horizonte.

Furtado, A.T; Carvalho, R.Q. 2005. Padrões de Intensidade Tecnológica da Indústria Brasileira: Um Estudo Comparativo com os Países Centrais. São Paulo Em Perspectiva, v.19, n.1, p. 70-84.

Galinari, R. 2006. Retornos crescentes urbano-industriais e spillovers espaciais: evidências a partir da taxa salarial no estado de São Paulo. 2006. Dissertação (Mestrado em Economia). Centro de Desenvolvimento e Planejamento Regional, Universidade Federal de Minas Gerais, Belo Horizonte.

Glaeser, E.L.; Kallal, H.D.; Scheinkman, J.A.; Shleifer, A..1992. Growth in cities. Journal of Political Economy, v. 100, n.6, p.1126-1152.

Glaeser, E.L., Maré, D.C. 2001. Cities and skills. Journal of Labor Economics, v.19, n.2, 316-342.

Henderson, J.V. 1974. The sizes and types of cities. American Economic Review, v.64, n.4, p.640-656.

Henderson, J.V.. 1994. Where does an Industry Locate?. Journal of Urban Economics, v.35, n.1, p.83-104.

Henderson, J.V.. 2003. Marshall's scale economies. Journal of Urban Economics, v.53, n.1, p.1-28.

Henderson, J.V, Kuncoro, A., Turner, M. 1995. Industrial development in cities. Journal of Political Economy, v. 103, n. 5, p. 1067-1090. 
Hatzichronoglou, T. 1997. Revision of the High-Technology Sector and Product Classification, OECD Science, Technology and Industry Working Papers, 1997/02, OECD Publishing.

IBGE. 1990. Divisão Regional do Brasil em Mesorregiões e Microrregiões Geográficas, v.1.

Jacobs, J. 1969. The Economy of Cities. New York: Vintage.

Jaffe, A. B.; Trajtenberg, M., Henderson, R. 1993. Geographic localization of knowledge spillovers as evidenced by patent citations, Quarterly Journal of Economics 63, p. 577- 598.

Krugman, P. 1980. Scale Economies, Product Differentiation, and the Pattern of Trade. The American Economic Review.70: 950-959.

Krugman, P. 1991. Increasing returns and economic geography. Journal of Political Economy, v. 99, n. 3, p. 483-499.

Kaldor, N. 1994. Causes of the slow rate of economic growth of the United Kingdom. In: KING, J. E. Economic growth in theory and practice: a Kaldorian perspective. Cambridge: Edward Elgar, p.279-318.

Lemos, M. B; Santos, F; Crocco, M. 2005. Condicionantes territoriais das aglomerações industriais sob ambientes periféricos. In: Diniz, C. C; Lemos, M. B. Economia e Território. Belo Horizonte: Ed. UFMG.

Lemos, Maurício B. 1988. Espaço e capital: um estudo sobre a dinâmica centre x periferia. Tese (Doutorado). Instituto de Economia, Unicamp, Campinas.

Lucas, R.J. 1988. On the mechanics of economic development. Journal of Monetary economics, v.22, n.1, p.3-42.

Lucas, R.J. 2001. Externalities and cities. Review of Economic Dynamics, v. 4, n.2, p.245-274.

Marshall, A. 1890. Principles of economics. London: Macmillan.

Melo, L.M.; Simões, R.F. 2011. Desigualdade Econômica Regional e Spillovers Espaciais: Evidências para o Nordeste do Brasil. Revista Econômica do Nordeste. v.42, n.1, p.9-24.

Menezes, T.; Azzoni, C. 2006. Convergência de salaries entre as regiões metropolitanas brasileiras: custo de vida e aspectos de demanda e oferta de trabalho. Pesquisa e Planejamento Econômico, v.36, n.3, p.449-470.

MP (Ministério do Planejamento, Orçamento e Gestão). 2008. Estudo da Dimensão Territorial para o Planejamento: Volume III - Regiões de Referência. Ministério do Planejamento, Orçamento e Gestão. Secretaria de Planejamento e Investimentos Estratégicos. Brasília: MP.

Ó Huallacháin, B.; Satterthwaite, M. 1992. Sectoral growth pattern at the metropolitan level: an evaluation of economic development incentives. Journal of Urban Economics, v. 31, p. 25-58.

Porter, M.E., 1990. The competitive advantage of nations. New York: The Free Press.

Romer, P. 1986. Increasing returns and long-run growth. Journal of Political Economy, v.94, n.5, p. 1002-1037.

Rosenthal, S.S., Strange, W.C. 2003. Geography, industrial organization, and agglomeration. Review of Economics and Statistics, v.85, n.2, p.377-393.

Rosenthal, S.S., Strange, W.C.. 2004. Evidence on the nature and sources of agglomeration economies.In Henderson, V.; Thisse, J.F. Handbook of urban and regional economics. v. 4, cap. 49, p. 2119-2172.

Silveira Neto, R. 2005. Concentração Industrial Regional, Especialização Geográfica e Geografia Econômica: Evidências para o Brasil no Período 1950-2000. RevistaEconômica do Nordeste, Fortaleza, v. 36, no 2,p.189208.

Topel, R. 1994. Regional markets and the determinants of wage inequality.American Economic Review, v.84, n.2, p.17-22.

Venables, A.J. 2006. Shifts in economic geography and their causes. Economic Review, Federal Reserve Bank of Kansas City, issue Q IV, p.61-85.

Wheaton, W.C., Lewis, M.J. 2002. Urban wages and labor market agglomeration. Journal of Urban Economics, v.51, n.3, p.542-562.

\section{Appendix}

Annex A.1 - Modern production services

Frame A.1. - Modern Production Services 


\begin{tabular}{|l|c|c|}
\hline \multicolumn{1}{|c|}{ Setors } & Code CNAE & Code CNAE \\
1.0 & 2.0 \\
\hline Telecommunications & $6420-3$ & 61 \\
\hline Finantial Intermediation & 65 & 64 \\
\hline Insurance and Pension Funds & 66 & 65 \\
\hline $\begin{array}{l}\text { Auxiliary Activities of Finantial Intermediation, Insurance and } \\
\text { Pensions Funds }\end{array}$ & 67 & 66 \\
\hline Computer Activities and Related Services & 72 & $62 / 63$ \\
\hline Research and Development & 73 & $72 / 74$ \\
\hline Legal Activies, Accounting and Busness Advisory & 741 & $69 / 70$ \\
\hline Archtecture, Engineering and Technical Advisory Specialist & 742 & 71 \\
\hline Testing of Materials and Products; Quality Analysis & 743 & 71 \\
\hline Advertising & 744 & 73 \\
\hline College Education & 803 & 853 \\
\hline Professional Education and Other Teaching Activities & 809 & 854 \\
\hline
\end{tabular}

Source: Adapted from Fontes (2006)

Annex A.2: Calculation of the regionalized real wages

For calculating the regionalized real wages, we created a Regional IPCA (Price Index) for the correction index. The IPCA is calculated nationally as a weighted average of indices for the metropolitan areas of Rio de Janeiro, Porto Alegre, Belo Horizonte, Recife, São Paulo, Belém, Fortaleza, Salvador, Curitiba, the Federal District and Goiânia. Therefore, we have indices for cities representing major regions of Brazil. Based on this, we revised the weighting of the IPCA at the national level, through a simple rule of three, so we can build indices at the regional level (see Table A.2).

The new weighting was used to build the Regional IPCAs through the weighted average of the indices for each city, according to the region to which it belongs. It works as follows: IPCA North with only Belém; IPCA Northeast with Fortaleza, Recife and Salvador; IPCA Southeast with Rio de Janeiro, Belo Horizonte and São Paulo; IPCA South with Curitiba and Porto Alegre; IPCA Midwest with Distrito Federal and Goiânia. That is, we created the following price indices for each region: IPCA North, IPCA Northeast, IPCA Southeast, IPCA South and IPCA Midwest.

Finally, wages were corrected using indicators by region -for example, the wages of industries in the Northeast were corrected by the IPCA Northeast for all years. Similarly, the wages of industries in the South were corrected by the IPCA South, and so on. Thus, this not only treated wages at constant prices, but also attenuated the bias caused by different price levels or cost of living in each region.

Frame A.2 - Rebalancing of the weights for the IPCA national regions.

\begin{tabular}{|l|lc|c|}
\hline \multicolumn{1}{|c|}{ Region } & Cities & Original Weight & Weights for weighted regions \\
\hline North & & $\mathbf{0 . 0 4 2}$ & $\mathbf{1 . 0 0 0}$ \\
& Belém & 0.042 & 1.000 \\
\hline Northeast & & $\mathbf{0 . 1 4 9}$ & $\mathbf{1 . 0 0 0}$ \\
& Recife & 0.041 & 0.275 \\
& Fortaleza & 0.039 & 0.262 \\
& Salvador & 0.069 & 0.463 \\
\hline Southeast & & $\mathbf{0 . 5 7 6}$ & $\mathbf{1 . 0 0 0}$ \\
& Rio de Janeiro & 0.137 & 0.238 \\
& Belo Horizonte & 0.108 & 0.188 \\
& São Paulo & 0.331 & 0.575 \\
\hline South & & $\mathbf{0 . 1 6 3}$ & $\mathbf{1 . 0 0 0}$ \\
& Curitiba & 0.074 & 0.454 \\
& Porto Alegre & 0.089 & 0.546 \\
\hline Midwest & & $\mathbf{0 . 0 7 1}$ & $\mathbf{1 . 0 0 0}$ \\
& Brasilia & 0.034 & 0.479 \\
& Goiânia & 0.037 & 0.521 \\
\hline
\end{tabular}

Source: Authors elaboration 